\title{
OLLADA CRÍTICA SOBRE A OBRA DE FEIJOO DE DUAS INTELECTUAIS GALEGAS: CONCEPCIÓN ARENAL E EMILIA PARDO BAZÁN
}

Xosé Ramón Barreiro Fernández

Universidade de Santiago de Compostela Real Academia Galega 

Despois da ruidosa polémica suscitada no século XVIII pola publicación da súa obra parecía que, por fin, se impoñía o xuízo e a cordura cando Sempere y Guarinos $^{1}$ (1785) escribiu que, a comezos do século XVIII, a ciencia en España estaba sumida en espesas tebras cando a aparición do Teatro crítico as fixo retroceder e chegou, de novo, a claridade.

Xa nos comezos do século XIX, Laborde² fai no seu coñecido «Itinerario» unha loanza xusta e ata xenerosa da obra do bieito galego. Blanco White, tan hipercrítico na valoración dos intelectuais españois, recoñece que a lectura das obras de Feijoo lle fixo mudar radicalmente os seus xuízos e, por iso, o tiña como unha das glorias de España ${ }^{3}$. Pero fixémonos que ambos os dous xuízos foron escritos e publicados no estranxeiro. En España, os críticos escatimaban os eloxios ou, mesmo, o silenciaban, actitude que non era exclusiva dos radicais defensores da tradición senón tamén dos renovadores, se é certo o xuízo atribuído a Lista y Aragón, para quen había que erguer unha estatua a Feijoo e logo queimar diante dela toda a súa obrá .

De feito e ata 1868, cando Feijoo entra forzosamente na gran polémica sobre a Ciencia en España, os escritos sobre o bieito galego foron escasos e mediocres 5 : rutineiras biografías para coleccións colectivas ${ }^{6}$; o curso encomendado a Alcalá Galiano no Ateneo de Madrid no ano 1845 sobre a historia da literatura española, francesa, inglesa e italiana do século XVIII, no que Feijoo aparece con máis sombras que luz; a desmedrada introdución de Vicente de la Fuente na publicación das obras de Feijoo para a Biblioteca de Autores Españoles, e o entusiasta, aínda

1 Sempere y Guarinos, Juan (1785): Ensayo de una biblioteca española de los mejores escritores del reinado de Carlos III, Madrid, Imprenta Real, I, 15.

2 Laborde, Alexandre-Louis-Joseph de (1808): Itinéraire descriptif de l'Espagne, et tableau élémentaire des différentes branches de l'administration et de l'industrie de ce Royaume, Paris, Chez H. Nicolle et Lenormant, $5 \mathrm{v}$.

3 Leocadio Doblado [pseudónimo de José María Blanco White] (1822): Letters from Spain, By don Leocadio Doblado, Londres.

4 Alude Menéndez Pelayo «al chiste de la estatua» que Lista divulgaba entre os seus amigos e discípulos. Vid. Menéndez Pelayo, Marcelino (1882): Historia de los heterodoxos españoles, Madrid, Imp. de F. Maroto e hijos, III, 78.

5 Para coñecer a evolución da valoración da obra de Feijoo é imprescindible acudir á monumental obra de Ramón Otero Pedrayo (1972): El Padre Feijoo. Su vida, doctrina e influencias, Orense, Instituto de Estudios Orensanos Padre Feijoo.

6 Diccionario Histórico ó Biografía Universal compendiada, Barcelona, 1832; Roca y Corner, J. (1847): Vida de Feijoo. Biografia Eclesiástica Completa, Barcelona. 
que pouco crítico, discurso de apertura do curso na Universidad de Oviedo no ano 1857 do profesor José María Anchóriz7.

Polo que respecta a Galicia, foron os provincialistas (a primeira xeración galeguista) os que se decataron da extraordinaria importancia de Feijoo e Sarmiento para a construción dun imaxinario liberal galeguista. Por iso, Faraldo, o líder do grupo, recuperou a Feijoo ${ }^{8}$ como paradigma da modernidade científica e española e expoñente do xenio galego. Pero foi Murguía ${ }^{9}$ quen mellor comprendeu a transcendencia da obra de Sarmiento e Feijoo na reconstrución do proceso identitario; Sarmiento pola súa importantísima contribución ao estudo do galego e Feijoo como o expoñente máis lúcido e xenial da contribución que á cultura española se fai dende a periferia.

Con estes antecedentes, compréndese que o claustro do Instituto de Ourense alertase, o 21 de outubro de $1875^{10}$, as autoridades para que se celebrase solemnemente o segundo centenario do nacemento do P. Feijoo. Mobilizadas as autoridades e forzas vivas da cidade, proxectaron diversos actos e a dedicación dunha estatua ao P. Feijoo. Entre estes actos foi, sen dúbida, o máis destacado a realización dun Certame, economicamente ben dotado (con 4000 reais), para o estudo crítico da obra do sabio bieito, tal e como xa expuxemos nun artigo ao que remitimos ${ }^{11}$. O proxecto da estatua cumpriuse, ao fin, no ano 1887 con novas celebracións ${ }^{12}$.

Tres foron os estudos presentados ao Certame de Ourense en 1876: o do catedrático da Universidad Central Miguel Morayta, do que prescindimos pola inter-

7 Anchóriz, José María (1857): Biografía y juicio de las obras que escribió el Ilustrísimo y Reverendísimo Padre Fray Benito Gerónimo Feijoo, Oviedo, Imp. y Lit. de Brid, Regadera y Comp.

8 Faraldo, Antolín (1843): «Feijóo. Su espíritu filosófico e influjo en la civilización española», El Recreo Compostelano (Santiago), 133-138.

9 Murguía, Manuel (1862): Diccionario de Escritores Gallegos, Vigo, Imp. Compañel, 199-212. Consideraba a Feijoo «la primera inteligencia que produjo nuestro país» (Idem, p. 206) e nas súas obras «se nota la dulzura y sentimiento propio de la raza a que pertenecía» (Idem, p. 205).

${ }^{10}$ El Heraldo Gallego (Ourense), 21-X-1875.

11 Barreiro Fernández, Xosé Ramón (2003): «O estudio crítico das obras do P. Feijóo de Pardo Bazán, Concepción Arenal e Miguel Morayta. O certame de 1876”, La Tribuna. Cadernos de Estudios da Casa Museo Emilia Pardo Bazán, I: 1, 47-96.

12 Pardo Bazán pronunciou o discurso para solemnizar a inauguración da estatua dedicada en Ourense ao P. Feijoo o 10-IX-1887 e publicouno en 1888 co título de «Feijoo y su siglo», en De mi tierra, A Coruña, Tipografía de La Casa de Misericordia, 141-219. 
pretación sectaria que fai da obra de Feijoo ${ }^{13}$; o de Concepción Arenal, «Juicio crítico de las obras de Feijoo»" ${ }^{14}$ e o de E. Pardo Bazán, «Estudio crítico de las obras del P. Feijoo» ${ }^{15}$. As diverxencias críticas proceden dos principios filosóficos que sustentan as autoras. Nos dous casos illaron a obra do P. Feijoo do contexto en que se producira, disecaron os seus discursos e procuraron resitualo no contexto dunha sociedade, a dos anos do Sexenio, no que unha xenerosa liberdade de pensamento permitiu que agromasen ideoloxías alternativas ao discurso tradicional.

Feijoo, canda a súa obra, converteuse nun obxecto de especulación intelectual. Con estas dúas obras non avanza nin un milímetro a investigación sobre o bieito galego, nin se procuran novas fontes nin se afonda nas súas ideas básicas. $\mathrm{O}$ único que lles interesaba a ambas as intelectuais galegas era se as ideas de Feijoo iluminaban unha nova vía para a interpretación do «ser» de España ou se foi quen consolidou a auténtica tradición depurándoa daquelas contaminacións perturbadoras da cultura tradicional. Por iso interesa moito fixar as dúas ideoloxías que determinan os xuízos sobre a obra de Feijoo.

\section{CONCEPCIÓN ARENAL E FEIJOO}

O pensamento social de Concepción Arenal inscríbese no liberalismo máis ortodoxo. A sociabilidade vén predeterminada pola natureza e por iso a división por clases é o gonzo de toda a vida social. As clases fundaméntanse na explotación dunhas sobre outras e cando se clama contra tal explotación non se comprende a

13 Morayta y Sagrario, Miguel: El Padre Feyjoó y sus obras, Valencia (s.a.), probablemente impreso en 1912 na imprenta de F. Sempere. Morayta pretende facer derivar da obra do bieito galego o alento de liberdade precursor do primeiro liberalismo español. Feijoo sería o pai de todo o radicalismo intelectual e mesmo político do século XIX español.

14 Arenal, Concepción (1877): «Juicio crítico de las obras de Feijoo», Revista de España (Madrid), LV, 110-117, 187-226 e 398-410; LVI, 348-365, e LVII, 174-201. Reeditado parcialmente en 1966 na Antología popular, selección e prólogo de Eduardo Blanco-Amor, Bos Aires, Ed. Galicia del Centro Gallego de Buenos Aires.

15 Pardo Bazán, Emilia (1877): «Estudio crítico de las obras de Feijoo por la Señora Doña Emilia Pardo Bazán», en Certamen Literario en conmemoración del Segundo Centenario del Nacimiento de Fray Benito Jeronimo Feijoo, autor del Teatro Crítico Universal, celebrado en Orense el 8 de octubre de 1876: obras premiadas, Madrid, Tipografía y estereotipia Perojo, 1877. 
inevitabilidade xa que «el problema no consiste en que los fuertes no abusen de los débiles, sino en que no haya débiles o haya pocos» ${ }^{16}$.

Como é posible nestas circunstancias conseguir a harmonía social que será o obxectivo principal da súa vocación? Non a través do Estado, que debe permanecer neutral e só actuar en situacións extremas (liberalismo ortodoxo radical), senón por outros medios. O primeiro deles é o fortalecemento das clases medias:

El grande elemento de fuerza, de inmortalidad de nuestra civilización, está en las clases medias, distantes de los extremos, que piensan y trabajan, compuestas de diferencias que se armonizan, de fuerzas que se equilibran, de desigualdades que no son esenciales; el gran peligro de nuestra civilización está en las clases extremas, en las diferencias que no pueden armonizarse sino para el mal, en las fuerzas cuya tendencia es a romper todo equilibrio; en todo género de miserias, explotables y explotados por todo género de opulencias ${ }^{17}$.

O segundo medio que empregar é a utilización dunha ideoloxía moral e relixiosa que propugne esta harmonía social entre clases tan distantes. E iso lógrase tanto a través dunha ideoloxía e do papel activo da intelectualidade como mediante unha acción constante en favor dos desfavorecidos, que foi a súa vocación persoal, exercida ás veces ata o heroísmo. O que rexeita é a revolución por ser un atentado contra a propia natureza.

Neste sinxelo esbozo do seu pensamento ${ }^{18}$ emerxe a responsabilidade social dos intelectuais, que poucas veces asumen a súa obrigación de intermediar na dialéctica social ata conseguir a harmonía social. Con frecuencia, ocultan as grandes

16 Arenal, Concepción (1997): «La igualdad social y política y sus relaciones con la libertad (1898)», en Celia Pereira Porto, A aportación de Concepción Arenal no marco do estado liberal español, A Coruña, Deputación Provincial, p. 97.

${ }^{17}$ Arenal, Concepción (1997): «El pauperismo», en Celia Pereira Porto, op. cit., p. 98.

18 En moitas das súas páxinas, Concepción Arenal mestura a pura racionalidade da súa teorización con elementos voluntaristas que non axudan a interpretar o pensamento. Por exemplo, o seu concepto da «moral» parece ser un concepto unívoco, cando conforme a súa concepción da sociedade e da autonomía das clases sociais debería aceptar que cada clase ten a súa propia moral e adecuarse a ela. Tampouco queda claro cando o Estado debe intervir na cuestión social. O feito de defender o principio da autonomía das clases e, ao mesmo tempo, a obrigación do Estado en propiciar a harmonía social deixa un amplo campo sen discernir. Ademais disto, a utilización da «caridade» como mecanismo social de harmonía pode entenderse nunha concepción tan racionalista que por si mesmo debería ser capaz de resolver os conflitos sen necesidade de acudir ao voluntarismo. 
diferenzas de clases, os abusos dunha minoría opulenta e a escravitude dos pobres. Servidores dunha clase á que pertencen, renuncian a denunciar os abusos sociais.

Precisamente, este é o obxectivo do seu estudo sobre Feijoo. Clérigo privilexiado, famoso polas súas obras, cun evidente peso social no seu tempo, seguiu tamén os ditados da intelectualidade contemporánea criticando só aqueles aspectos máis externos, pero silenciando as causas da opresión, salvando en todo momento tanto a Igrexa, á que pertencía, como a monarquía, que tan pródiga foi con el. Por iso é moi difícil entender que o xuízo formulado por Concepción Arenal non sexa un retrospectivo axuste de contas.

Sería en certa maneira inútil buscar unha correlación entre o discurso de C. Arenal e a súa militancia política. Naceu e creceu nunha familia liberal. Casou no ano 1848 con Fernando García Carrasco, tamén liberal, e os dous colaboraron no xornal liberal La Iberia; mantén unha sólida amizade con Salustiano Olózaga e foi íntima amiga de Juana de Vega, condesa de Espoz y Mina, quen no seu testamento lle deixa un importante legado para ela e os fillos. Toda a súa personalidade se move, pois, nun contexto político liberal. Pero sorprendentemente, Concepción Arenal elabora un discurso completamente á marxe da filosofía liberal do seu partido. Onde os liberais destacan a soberanía nacional como eixe central, C. Arenal remarca o papel fundacional do plan divino na orixe e conformación da sociedade. Onde o pensamento liberal salienta o principio da laicidade para corrixir os desequilibrios sociais do absolutismo, C. Arenal defende que a relixiosidade é o motor central do proceso sociolóxico e histórico. $\mathrm{E}$, finalmente, cando os liberais deseñan un modelo de Estado centralista, capaz de cambiar radicalmente as estruturas da orde social, C. Arenal (fiel á ortodoxia dun capitalismo ortodoxo) reduce o papel do Estado, que debe respectar sen se inmiscir máis que nos casos extremos o xogo e a dialéctica das clases sociais, porque «lo que hay que desear es que el Estado haga lo menos posible de aquello que es preciso hacer y que, sin su intervención, se hace bien; lo que hay que temer es que lo que es necesario no lo haga nadie, o lo haga quien lo hace peor» ${ }^{19}$.

Cando se integra na Institución Libre de Enseñanza, sen abandonar as tarefas caritativas e a súa entrega en favor da redención dos presos, parece que se lle agu-

19 Arenal, Concepción (1997): «La instrucción del pueblo. Memoria premiada por la Real Academia de Ciencias Morales y Políticas en el concurso de 1878», en Celia Pereira Porto, op. cit., p. 102. 
diza o senso crítico sobre as persoas e institucións insensibles á dor dos vencidos e castigados.

É nese momento cando elabora o seu traballo sobre Feijoo, referente para ela do que debe e non debe ser unha mente privilexiada. Por iso a súa análise do comportamento do monxe bieito merécelle aprobacións e reprobacións porque, sendo un faro que ilumina o seu tempo histórico, non só proxecta luz senón tamén sombras e tebras.

A autora comprométese a non se deixar seducir por «fanatismo de partido ni de escuela» e lembra que «nuestro espíritu, animado por el deseo de la justicia, puede elevarse a esas serenas regiones donde se comprende y se hace» ${ }^{20}$. Malia estudar a Feijoo «imparcialmente, sin idea preconcebida; si hemos tomado nota de sus aciertos como de sus errores; si el amor a la verdad que a él guiaba nos ha guiado», non estaba segura de acertar no retrato e na valoración de Feijoo ${ }^{21}$.

\section{Feijoo, filósofo}

Si de filósofo se califica a un hombre cuya razón es capaz de elevarse a metafísicas abstracciones y profundizar en el estudio de la naturaleza humana, observador analítico, lógico, dispuesto a pedir a la duda sus motivos y a la afirmación sus pruebas [...] era un filósofo Feijoo ${ }^{22}$.

Pero se por filósofo se entende levar a investigación e a análise ata os últimos confíns, que conceptos como Deus, natureza e humanidade estean tamén sometidos ao raciocinio, entón Feijoo non foi filósofo porque a maior parte destas cuestións as recibiu resoltas pola autoridade da Igrexa, á que en todo caso se somete. Ten que «retraerse de tratar cuestiones fundamentales en las que el círculo de lo opinable era cada vez más reducido» ${ }^{23}$.

Insatisfeito coas distintas escolas filosóficas, «ciudadano libre de la república literaria, ni esclavo de Aristóteles ni aliado de sus enemigos, escucharé siempre, con preferencia a toda autoridad privada, lo que me dicten la experiencia

\footnotetext{
20 Arenal, Concepción (1877): «Juicio crítico de las obras de Feijoo», Revista de España, LV, 111.

${ }^{21}$ Ibidem.

22 Idem, 187.

${ }^{23}$ Ibidem, onde se recolle o texto de Feijoo.
} 
y la razón» ${ }^{24}$ e empregando unha imaxe metafórica, exculpatoria da súa indecisión, «mientras el mar no se aquieta, es prudente detenerse a la orilla; quiero decir, mientras no se descubre rumbo, libre de grandes dificultades para engolfarse dentro de la naturaleza, dicta la razón mantenerse en la playa, sobre la arena seca de la Metafísica» amparado neste punto pola "Iglesia universal, la cual es cierto que no puede errar en materias de fe, no por imposibilidad antecedente que se siga a la naturaleza de las cosas, sino por la promesa que Cristo la hizo de su continua asistencia y de la del Espíritu Santo en Ella» ${ }^{25}$. Por conseguinte, escribe C. Arenal, «el origen de todo conocimiento debe ser el estudio, la observación, la experiencia, no admitiendo contra ellos autoridad privada, pero sometiéndose incondicionalmente a la de la Iglesia».

Pronúnciase Feijoo con evidente desdén contra os filósofos da antigüidade, nos que nada ve aproveitable (Demócrito, Epicuro, Zenón, Pitágoras, etc.). Escribe:

Todos estos siglos se perdieron para la filosofía, y toda la ocupación de los filósofos que florecieron en ellos se puede decir que fue una mera ociosidad, pues no hicieron otra cosa que tomar sueños por realidades, sombras por luces, ilusiones por aciertos, parelias por soles. Si lo que dieron a especulaciones vagas dieran a observaciones experimentales, ¡oh! que gazofilacio de física hubieran dejado a la posteridad, en vez de los inútiles harapos que hemos heredado de ellos! ${ }^{26}$

Tivo Feijoo a oportunidade de redactar un curso completo de Filosofía, que lles impartiu aos seus alumnos do colexio dos bieitos de Lérez (Pontevedra) durante os cursos comprendidos entre 1704 a 1707 (Lóxica, Metafísica, Filosofía Natural e Psicoloxía). Dado o sistema empregado entón nas clases, nas que o profesor ditaba o texto, temos a garantía de que o Curso recollido polo alumno

${ }^{24}$ Idem, 188.

25 Ibidem, onde se recolle o texto de Feijoo.

${ }^{26}$ Idem, 190. As "parelias» eran unha especie de meteoritos ou soles aparentes (Diccionario de la lengua castellana compuesto por la Real Academia Española, reducido á un tomo para su mas fácil uso [Madrid, 1780, 690]). 
frei Matías de la Vega, conservado e publicado por R. López Vázquez ${ }^{27}$, contén ipsissima verba o texto ditado por Feijoo.

Aínda que López Vázquez destaca a «brevidade, claridade, coherencia, síntese, incluso beleza, sinxeleza e profundidade» do texto, en realidade nada hai nel que non atopemos noutros cursos que coñecemos, sempre a través de alumnos, contemporáneos ou posteriores. O curso de Feijoo sométese á ratio docendi da orde beneditina e nel non se atopa o resplandor dunha xenialidade ou dunha posición arriscada. Pura vulgaridade escolástica.

Conclúe C. Arenal dicindo que Feijoo «tuvo facultades para ser un filósofo, pero que no ha podido hacer más que manifestar disposiciones y tendencias filosóficas» ${ }^{28}$.

\section{Teólogo e moralista}

Con moita chanza dinos Feijoo que decidiu non escribir tratados de Teoloxía porque «¿Que puedo yo adelantar en asuntos que con tanta reflexión meditaron hombres insignes?». Só conseguiría, engade, amontoar nos faios de tres ou catro celas os centos de libros non vendidos. Por utilidade, pois, negouse sempre a escribir libros de Teoloxía.

Pero, como destaca Concepción Arenal, esta decisión ten outras motivacións: non ten que someterse aos catro cadeados ou censuras: a da Orde, a do bispo ordinario, a do Rei e a da Inquisición; catro cadeas que facían desistir o ánimo máis temperado.

Se non escribiu grosos tratados teolóxicos, derramouse, en troques, en consellos e en críticas sobre o uso improcedente da relixiosidade. En ton distendido, irónico e, ás veces, cotifeiro, sorprendíase da eficacia de Nosa Señora de Nieva, que inmunizaba os seus fieis contra as tempestades e, sobre todo, contra os raios. A venda de estampas, medallas e o rito contaxioso de tocar cun pano a imaxe eran un «milagroso preservativo para cualquiera que con religiosa veneración la lleva consigo».

\footnotetext{
27 López Vázquez, Ramón (1995): O Padre Feixoo, escolástico, Santiago de Compostela, Centro de Investigacións Lingüísticas e Literarias Ramón Piñeiro, Xunta de Galicia.

28 Arenal, Concepción (1877): «Juicio crítico de las obras de Feijoo», Revista de España, LV, 202.
} 
Da mesma maneira ironiza sobre as flores de San Luis do Monte (Asturias), flores milagrosas que resultou que nin eran milagres nin sequera flores...

Tamén atacou a práctica dos exorcismos, cuxa falsidade el mesmo puido comprobar cando ante unha suposta posuída «empecé mis conjuros con versos de Virgilio, de Ovidio, de Claudiano y de otros poetas [...]. Singularmente al empujarle la pomposa introducción de la Farsalia de Lucano [...], casi llegué a temer que de veras se espiritaba», logo acercoulle unha chave dun escritorio, coma se fose unha reliquia, e creceron os seus espasmos "como quien está bien ejercitada en este juego. En fin, sobradamente enterado del embuste de esta mujercilla, la despedí».

Esta liberdade de espírito, esta valentía desaparecía cando as súas opinións rozaban non a ortodoxia senón o poder coactivo da Igrexa. No seu discurso «Música de los templos» bramaba contra a utilización dos violíns dentro das igrexas, pero bastou que Benedicto XIV os permitise para que «retractara gustoso lo que escribí sobre este punto». Convencido da cientificidade do sistema copernicano, renegou del por ser oposto á Sagrada Escritura. Por iso non estraña a defensa da permanencia da Inquisición e non só en España senón en todo o mundo, porque o sucedido noutros lugares «nos da a conocer la necesidad que hay en otros reinos de erigir para semejantes causas el rectísimo tribunal de la Inquisición, que acá, por gran dicha nuestra, tenemos» ${ }^{29}$.

Por todo isto Concepción Arenal conclúe que «Feijoo compró la paz a costa de la lógica; que su espíritu contuvo los ímpetus de independencia; que se sometió todo entero; que el religioso triunfó del pensador, prefiriendo la inmolación a la rebeldía ${ }^{30}$.

\section{Feijoo, xurista e canonista ${ }^{31}$}

Dúas son as cuestións que reclaman a preferente atención de Concepción Arenal: a xustiza, e máis en concreto a xustiza no ámbito penal, e o xuízo sobre o poder absoluto dos reis.

29 Arenal, Concepción (1877): «Juicio crítico de las obras de Feijoo», Revista de España, LV, 209.

30 Idem, 213.

31 É imprescindible reler as afirmacións de Feijoo sobre a xustiza tendo en conta a magnífica monografía do profesor Luis Rodríguez Ennes El padre Feijoo y el derecho de su tiempo: una visión premonitoria de problemas candentes en la actualidad, Vigo, Consello Social da Universidade, 2013. 
Recoñece Concepción Arenal que bastaría a publicación do estudo de Feijoo Balanza de Astrea para consideralo un intelectual de criterio recto. Porén, hai aspectos en que a sensibilidade humanista do bieito non sempre se sostén. Tal é o caso da tortura xudicial, da pena de morte, etc. Referíndonos aos dous temas centrais: o da tortura como proba xudicial e a pena de morte, o pensamento de Feijoo é bastante confuso e, mesmo, parece contraditorio.

Feijoo pronúnciase contra a tortura porque case sempre resultaba ineficaz como medio de proba xudicial, pero non dita unha sentenza reprobatoria dende a ética contra a tortura en canto tal, como si fai o P. Sarmiento ${ }^{32}$; debendo deducir que, no suposto de que a tortura fose un instrumento eficaz para o descubrimento do crime, o seu uso sería lexítimo.

Polo que respecta á pena de morte, sen ser un defensor per se, entendía que a súa aplicación precavía e, por conseguinte, impedía moitos outros crimes ${ }^{33}$.

Para C. Arenal estes posicionamentos revelan que Feijoo non tiña unha noción exacta da xustiza en materia criminal, porque, aínda que teoricamente defende a dobre finalidade da pena (resarcimento da xustiza obxectiva e corrección do delincuente), na práctica Feijoo esquece a segunda finalidade, especialmente nos delitos de maior transcendencia pública. Por iso defende que nos crimes de herexía ou de lesa maxestade o restablecemento da xustiza obxectiva era tan urxente que o xuízo debería dilixenciarse con toda rapidez, «aun a riesgo de que sea condenado un inocente». Do que conclúe Arenal que Feijoo, nestes casos, «no veía más que el derecho de la sociedad, el del reo desaparecería muchas veces en teoría y, con mayor frecuencia, en la práctica» ${ }^{34}$.

Defende Feijoo un caso no dereito penal canónico tan inhumano que pon de manifesto o servilismo das mentes máis lúcidas na Igrexa. A causa dunha «Constitución do Papa Pío V» (1566), ordenábase que, se os médicos advertían no enfermo síntomas de gravidade e a posibilidade de morrer, se o enfermo non solicitaba confesión, o médico ipso facto debía deixalo sen atención ningunha, ameazándoo en caso contrario coa pena de excomunón e de denuncia ante o colexio médico para que expulsasen o doutor, impedíndolle o exercicio da medi-

32 Rodríguez Ennes, Luis (2013): El padre Feijoo y el derecho de su tiempo: una visión premonitoria de problemas candentes en la actualidad, Consello Social da Universidade de Vigo e Dykinson, 62-65.

33 Idem, 69.

34 Arenal, Concepción (1877): «Juicio crítico de las obras de Feijoo», Revista de España, LV, 401. 
cina. Esta Constitución tan cruel e inhumana aínda se mantén na reedición das Constitucións Sinodais de Ourense do ano 1843 (Lib. V, tít. VI, const. 4, 273-274).

Feijoo escribe ao respecto: «Lo que en ella pretende el Santo Legislador [refírese a Pío V] no es que el médico abandone al enfermo [...] sino cuando los rehusa [os sacramentos] con negligencia o repugnancia voluntaria y libre». E isto faise "porque el miedo de que le falte la medicina del cuerpo le reduzca a implorar la del alma ${ }^{35}$. Escusa que non pode borrar a nota de inhumanidade de tal censura.

Polo que atinxe á estrutura do poder político, moitos comentaristas déixanse engaiolar por expresións como que os reis son criaturas idénticas coma as demais, pero esquecen que o pai bieito nunca rexeitou a monarquía absoluta, nin a orixe divina do poder monárquico, nin o dereito hereditario como fórmula de transmisión deste absoluto poder. Tampouco alude nunca ao dereito de insubordinación, nin ao tiranicidio, polo menos como o contempla Santo Tomás ${ }^{36}$. Limitacións que Concepción Arenal explica empregando a máxima do propio Feijoo «No es lo que se siente lo que se dice, cuando es delito decir lo que se siente».

\section{Feijoo e a valoración das mulleres}

No seu discurso Defensa de las mujeres é consciente do grave empeño en que se poñía porque «defender a todas las mujeres viene a ser lo mismo que ofender a casi todos los hombres, pues raro hay que no se interese en la precedencia de su sexo con desestimación del otro». E tanto repetiron os homes «que las mujeres son de cortísimo alcance, que a muchas, si no a las mas, ya se lo han hecho creer».

Para probar la igualdad de las almas en los dos sexos, y si no la identidad, la equivalencia de facultades, nuestro autor combate en todos los terrenos y echa mano de la anatomía, de la fisiología, de la historia, de la lógica y con argumentos concluyentes combate a tantos autores que con Aristóteles a la cabeza, han considerado a la mujer no solo como inferior al hombre sino como un animal imperfecto ${ }^{37}$.

35 Idem, 209.

36 Idem, 407.

37 Idem, 194-195. 
Porén, a defensa filosófica da igualdade da muller con respecto ao home non implicaba a asunción da igualdade de dereitos por parte de Feijoo ou, polo menos, non consta na súa obra ${ }^{38}$. Moito máis avanzado neste punto era Sarmiento cando definía que a diferenza entre homes e mulleres non era de natureza senón de educación.

Recoñecendo todo isto, Concepción Arenal critica duramente a Epístola de Feijoo a unha moza que lle pregunta se pensa que é mellor o estado de casada ou a profesión relixiosa. Ante a resposta do pai bieito en favor do convento, rebélase a escritora ferrolá porque no fondo Feijoo lle está a recomendar «la comodidad, el ocio y el sosiego» apartándoa da loita cotiá. Non pode ser considerado «estado perfecto el de una criatura que no ama, ni piensa, ni trabaja», que así pode definirse «a una monja de vida contemplativa». Máis aínda, chamarlles ás mulleres que optan polo convento «esposas de Cristo» non deixa de ser «una ficción medio ridícula, medio impía». En troques, valora as monxas activas, comprometidas coa sociedade e moi en especial as Fillas ou Monxas da Caridade ${ }^{39}$.

\section{Recapitulación final}

A fisionomía moral de Feijoo era «bella, noble, imponente» pero asume todas as contradicións do seu tempo histórico. O espírito innovador e aparentemente revolucionario aparece sempre coutado, controlado polos poderes dunha sociedade moi atenta a mobilizar os mecanismos de persecución cando intuían que determinadas ideas podían danar a estrutura ideolóxica dun sistema creado para soster a alianza entre o Trono e o Altar, que era toda a base dunha sociedade en que os distintos roles estaban perfectamente distribuídos.

Xa se comprende que un traballo destinado a glorificar a Feijoo non podía facer esta crítica. Por iso o xurado de Ourense o aprobou, non así o da Universidad de Oviedo, que ditaminou que quedase «unánimemente excluido» pola «marcada tendencia que el autor revela en el curso del erudito trabajo a hacer partícipe de sus racionalistas ideas al ilustre monje, interpretando de una manera violenta el espíritu de sus inmortales obras en algunos de los pasajes que cita».

38 Rodríguez Ennes, Luis (2013), op. cit., 199-200.

39 Arenal, Concepción (1877): "Juicio crítico de las obras de Feijoo», Revista de España, LV, 222. 


\section{PARDO BAZÁN E FEIJOO}

Interesa moito coñecer as súas fidelidades ideolóxicas básicas e a súa militancia para poder interpretar axeitadamente a versión que nos ofrece da obra do P. Feijoo.

Cando escribe esta obra militaba no carlismo, ao que lle prestara apoio económico e propagandístico, aínda que a súa intelixencia e sensibilidade lle impedían asumir certos obxectivos como o da recuperación da Inquisición.

Aínda que a partir de 1888 e como consecuencia da postura hostil do sector carlista de Nocedal fai unha intelixente retirada das posturas máis radicais, podemos asegurar que nunca renunciou a unha silenciosa militancia en favor da Causa $^{40}$.

De como puido conciliar esta militancia e, ao mesmo tempo, gozar da estima e amizade dos homes de prol da Institución é algo que ignoramos e preferimos non aventurar hipóteses.

Cando só tiña 26 anos escribiu uns apuntamentos titulados «Teoría del Absolutismo», que demos a coñecer hai algún tempo ${ }^{41}$. Estamos diante da primeira redacción para un traballo máis amplo e que afortunadamente non chegou a concluír nin a publicar porque a obra, tal e como a concibía, superaba en moito a súa capacidade, aínda recoñecéndolle a dona Emilia todo o seu moito saber.

Seguindo a pegada do tradicionalismo francés, especialmente a De Bonald, ao que sorprendentemente nunca cita, dá por suposto que a sociedade está sometida a unhas leis marcadas ab initio polo creador polas que deben rexerse os Estados. Deus elixiu a monarquía como a forma de goberno das sociedades, pero afastada do despotismo e limitada por disposición divina polos dereitos da persoa, así mesmo fixados por Deus, e pola convivencia harmónica con outras institucións, como a Igrexa, que garantía a ortodoxia do proxecto de goberno da monarquía absoluta.

40 Barreiro Fernández, Xosé Ramón / Patricia Carballal Miñán (2007): «Emilia Pardo Bazán y el debate entre "La Fe" y "El siglo futuro"», en Xosé Manuel González Herrán, Cristina Patiño Eirín e Ermitas Penas Varela (eds.), Emilia Pardo Bazán, el periodismo. Actas del III Simposio, A Coruña, Real Academia Galega / Fundación Caixa Galicia, 131-151.

${ }^{41}$ Barreiro Fernández, Xosé Ramón (2005): «A ideoloxía política de Emilia Pardo Bazán», La Tribuna. Cadernos de Estudios da Casa-Museo Emilia Pardo Bazán, 3, 39-69. 
Por conseguinte, a chamada soberanía nacional e a súa capacidade para estruturar a convivencia política deben ser consideradas unha corrupción do plan divino e as limitacións impostas á Igrexa a través do laicismo son outros atentados da sociedade civil contra o plan divino.

O absolutismo non é, por conseguinte, a ditadura nin a tiranía. É un sistema que funcionou con eficacia durante centos de anos, porque a propia lei divina se encargou de poñer límites a este poder.

Se mesturamos esta ideoloxía coa súa militancia carlista, despréndese un pensamento radicalmente oposto ás conquistas do liberalismo dende a Revolución Francesa e a constitución dos Estados Unidos de América, é dicir, un pensamento involucionista que non tiña aplicación xa en ningún dos países máis avanzados.

Iso explica a fácil adaptación de dona Emilia ao tradicionalismo e como a súa achega foi positivamente valorada, agás a aproximación ao naturalismo e, sobre todo, a amizade cos innovadores da Institución Libre de Enseñanza, que tan frutífera lle foi de cara á crítica.

No ano 1874 Pardo Bazán descobre a Feijoo ${ }^{42}$ e queda seducida. E o «cíclope» capaz de erguer sobre as súas costas a modernización do país é un «Proteo científico», un home «omnisciente que no deja rincón que no registrase». Del arranca a modernidade da vida científica de España. É, en fin, o primeiro crítico do que se pode gabar España e ata hoxe (escribe isto en 1876) non foi igualado ${ }^{43}$.

Ao igual que no ano 1882 Menéndez Pelayo relativizara non pouco os méritos de Feijoo ${ }^{44}$, Pardo Bazán, no discurso pronunciado en Ourense no ano 1887, maniféstase máis comedidamente, pero mantén a tese central de que na escurida-

42 Pardo Bazán, Emilia (1877): «Estudio crítico de las obras de Feijoo por la Señora Doña Emilia Pardo Bazán», en Certamen Literario en conmemoración del Segundo Centenario del Nacimiento de Fray Benito Jeronimo Feijoo, autor del Teatro Crítico Universal, celebrado en Orense el 8 de octubre de 1876: obras premiadas, Madrid, Tipografía y estereotipia Perojo, 161-162.

43 Barreiro Fernández, Xosé Ramón (2003): «O Estudio Crítico das obras do P: Feijoo de Pardo Bazán, Concepción Arenal e Miguel Morayta. O certame de 1876», La Tribuna. Cadernos de Estudios da Casa Museo Emilia Pardo Bazán, 1, 80.

44 Menéndez Pelayo acusa os críticos de descoñecer a cultura do século XVII por enaltecer excesivamente o P. Feijoo. Vid. Historia de los Heterodoxos, Madrid, Imprenta de F. Maroto e hijos, 67-90. 
de da cultura ibérica «puede asegurarse que la noche de la decadencia se ilumina con resplandor de aurora $»^{45}$.

\section{Feijoo como filósofo}

Como no seu día escribiu Ardao ${ }^{46}$, pretender expoñer o pensamento de Feijoo nun esquema sistemático, captando a súa articulación lóxica, é unha empresa imposible. Non obstante, quedan refachos luminosos que preanuncian a posibilidade dun corpus en que, utilizando o método empírico, podería aproximarse a unha filosofía da ciencia. Pero incluso no aspecto científico carece da coherencia suficiente que responde a un sistema. Coñece as teorías de Newton, pero non as segue porque, segundo a benévola interpretación de Pardo Bazán, refusaba integrarse nunha escola para poder seguir sendo independente. Asume o escepticismo pero non como un sistema para aproximarse á ciencia, senón como unha especie de reserva do seu xuízo que protexe a súa liberdade para se inclinar en cada caso polas opcións que máis o convencesen.

O que valora Pardo Bazán moi positivamente é a ortodoxia de Feijoo: «No contienen los escritos de Feijoo proposición que, recta y caritativamente interpretada, lastime en lo más mínimo la integridad del dogma» e levando as augas ao seu rego engade: «Feijoo es la prueba clara de la amplitud que otorga al pensamiento el catolicismo y del vasto campo que deja en las materias opinables $»^{47}$.

\section{Feijoo literato}

Sorprende o escaso espazo que se lle dedica a Feijoo nas historias da literatura española cando Azorín non dubidou en cualificalo como «generador de la prosa moderna».

\footnotetext{
45 Discurso de 1887, en De mi tierra (1888), A Coruña, Tipografía de La Casa de Misericordia, 153). Na disertación, Pardo Bazán recolle as críticas formuladas por Menéndez Pelayo, pero no canto de as refutar pediu un aplauso ao público asistente en honor de D. Marcelino, que, por suposto, o público non negou. Evitou desta forma que se molestase Menéndez Pelayo, evitando os dardos da súa crítica.

46 Ardao, Arturo (1962): La filosofía polémica de Feijoo, Bos Aires, Losada.

47 Pardo Bazán, Emilia (1888): De mi tierra, A Coruña, Tipografía de la Casa de Misericordia, 175.
} 
Pardo Bazán tampouco manifesta entusiasmo pola súa prosa, destacando os «largos y fastidiosos párrafos [...] galicismos y escolasticismos que desfiguran y afean extrañamente el conjunto» ${ }^{48}$, pero procurou explicar o seu estilo descoidado polo seu afán de acercarse ao gran público e porque preferiu sempre a orixinalidade evitando seguir os modelos literarios do seu tempo.

Feijoo empregou un discurso "gacetal» (propio das gazetas populares) para popularizar máis o seu discurso, procurando «facilidad y provecho». Por iso, podemos asegurar que gran parte do éxito de Feijoo se debeu a adoptar $o$ ensaio como medio de comunicación ${ }^{49}$, entendendo por ensaio unha composición breve sobre temas de actualidade, sen pretensións de exhaustividade, sen someterse aos canons formais de multiplicar as citas e aparentemente carecendo dunha estrutura determinada ${ }^{50}$. Foi, pois, o primeiro gran ensaísta en España.

No discurso de 1887, Pardo Bazán mantén as mesmas ideas. O estilo literario de Feijoo explícao el mesmo cando di que a forma de escribir «se me vino, tal como lo veis, no lo busqué yo», é dicir, é un produto da natureza e non da arte ou do artificio.

Grazas a este estilo, Feijoo foi o autor máis lido no seu tempo, mentres que os escritos do P. Isla, «más correcto» no seu estilo, apenas se len no presente.

48 Pardo Bazán, Emilia (1877): «Estudio crítico de las obras de Feijoo por la Señora Doña Emilia Pardo Bazán", en Certamen Literario en conmemoración del Segundo Centenario del Nacimiento de Fray Benito Jeronimo Feijoo, autor del Teatro Crítico Universal, celebrado en Orense el 8 de octubre de 1876: obras premiadas, Madrid, Tipografía y estereotipia Perojo, 25.

49 Álvarez Barrientos, J. (1995): «El ensayo del siglo XVIII», en V. García de la Concha (dir.), Historia de la Literatura Española, I, Madrid, Espasa-Calpe, 61-68.

50 Gómez Martínez, J. L., Teoría del ensayo, Salamanca, Universidad, 1981. O profesor e vello amigo Mestre Sánchez axuíza a Feijoo nun ton brusco que, as veces, usa: «Feijoo es el creador del ensayo, mérito suyo indiscutible, en el que es dueño absoluto y luce sus cualidades de perspicacia, gracia e ingenio en un género en la medida de su capacidad. Para ello, Feijoo necesita hablar de omini se scibile de filosofía sin especiales conocimientos metafísicos, de derecho sin ser jurista, de historia sin haber pisado un archivo ni haber manejado documento original alguno, de medicina sin haber observado a un enfermo... Es la cruz del ensayista...» (Mestre, A. [1976]: Despotismo e Ilustración en España, Barcelona, Ariel, 29). 


\section{Feijoo moralizador e moralista}

Distingue Pardo Bazán en Feijoo dúas cuestións: a loita do pai bieito contra a superstición e os falsos saberes e o que poderiamos entender por doutrina positiva sobre a moral, unha especie de "metafísica de los hábitos sociales»"1.

Feijoo dedicou boa parte dos seus escritos a denunciar as supersticións e as necidades espalladas como verdades entre a intelectualidade. Polo seu «desinteresado culto a la verdad», librou duras batallas contra todos aqueles, sen excluírmos as ordes relixiosas, que se beneficiaban da superstición popular.

Xa como moralista, procurou humanizar os ditados da lei moral aconsellando modelos de vida máis acordes coa vida do pobo. Por iso refuga do pietismo que na práctica se convertía nunha especie de cerimonialismo (misas, procesións, triduos, novenas, etc.), que desviaban a atención preferente dos cristiáns, que debían concentrarse nos oficios e responsabilidades de traballo, e non no culto ou relixión.

Pardo Bazán compara, por exemplo, a moral matrimonial aparecida en La perfecta casada, de frei Luis de León, coas normas que con respecto ao matrimonio dá Feijoo e conclúe que na obra de frei Luis dificilmente se atopará un modelo válido para o século XVIII.

No seu traballo sobre La urbanidad, Feijoo procura a simplicidade, a sensatez e a racionalidade: «El echar en olvido la felicitación de un día de cumpleaños era suficiente motivo para que se indispusiesen las familias [...] en que un viaje de veinticuatro horas exigía una despedida general y en que en los saraos se estaba como en un entierro ${ }^{52}$ eran algunhas das situacións que Feijoo criticaba para que as relacións sociais fosen sempre máis humanas.

\footnotetext{
51 Pardo Bazán, Emilia (1877):, «Estudio crítico de las obras de Feijoo por la Señora Doña Emilia Pardo Bazán», en Certamen Literario en conmemoración del Segundo Centenario del Nacimiento de Fray Benito Jeronimo Feijoo, autor del Teatro Crítico Universal, celebrado en Orense el 8 de octubre de 1876: obras premiadas, Madrid, Tipografía y estereotipia Perojo, 60 e ss.

52 Idem, 67-68.
} 


\section{Feijoo e as cuestións xurídico-políticas}

Non interpretou acertadamente Pardo Bazán a postura de Feijoo sobre a proba xurídica do tormento. Como xa expuxemos, Feijoo entendía que era ineficaz na maior parte dos casos, pero reservábaa para aqueles delitos gravísimos que debían ser condenados de inmediato polas repercusións sociais.

Engade que a pena de morte «túvola por indispensable pilar para el mantenimiento del orden social» ${ }^{53}$.

«No puede negarse —escribe Pardo Bazán— en manera alguna que en Feijoo hay un crítico y un reformador, pensar otra cosa sería desconocerlo. Pero fuera también no comprenderle, o comprenderle mal, el imaginar que a todo lo que tiene de reformador y de crítico se agrega ni un átomo de revolucionario» e comparando a Feijoo cos enciclopedistas que non dubidan en «improvisar» institucións e leis de acordo coa «efervescencia de la opinión» apláudeo por non dedicar nin un parágrafo a atacar a organización social de España, e por iso «en todos sus escritos se advierte una completa y sincera adhesión a los poderes soberanos de su patria» ${ }^{54}$.

Está claro que Pardo Bazán reutilizando a Feijoo está defendendo un modelo de sociedade de tipo absolutista. Separa para iso dous conceptos: interpretar o mundo e cambialo. Probablemente, tal xuízo non sería aceptado polo propio Feijoo, quen criticou con fereza os malos costumes, as supersticións e a falsa ciencia para construír un país novo. Certo é que foi respectuoso cos principios básicos daquela sociedade, mais non porque se compracese neles, senón por imposibilidade de derruílos.

\section{Conclusión}

Pardo Bazán glorifica a Feijoo malia recoñecer as limitacións en cuestións puntuais. Destacou a súa modernidade científica e valoraba a súa coraxe para extirpar as supersticións e falsos saberes, pero sobre todo que compatibilizase esta

\footnotetext{
53 Idem, 122.
}

54 Idem, 126. 
modernidade co maxisterio da Igrexa. Pardo Bazán fixo unha hábil glorificación de Feijoo envolta nun fermoso estilo literario.

O texto que presentou dona Emilia ao premio revela descoñecemento da cultura española dos séculos XVII e XVIII, elude habilmente as cuestións máis polémicas de tipo teolóxico, xurídico e histórico, e hai un excesivo tratamento parafrástico dos textos de Feijoo (defecto en que coincide con C. Arenal) sen dúbida para poder presentar un texto que ocupa 148 páxinas impresas.

De todo isto era consciente Pardo Bazán, que, nunha carta a Menéndez Pelayo ${ }^{55}$, lle recoñece que o seu libro era «tan defectuoso y malo que hasta reeditarlo corrigiéndolo no me atrevo en modo alguno a mandárselo».

Non nos consta que fixese tales correccións e así quedou o libro para sempre. «Este librucho que la Comisión de Orense, por fortuna mía, archivó y no puso a venta ${ }^{56}$, engade Pardo Bazán.

\section{RECAPITULACIÓN FINAL}

No ano 1877, con motivo do certame de Ourense asistimos a un anticipo da loita que se está fraguando e que se coñecerá como o debate sobre a Ciencia Española. As dúas intelectuais galegas (as dúas tiñan informadores en Ourense que probablemente eran sabedores da intención de se presentaren ambas e así llelo comunicarían ás súas protexidas) eran conscientes de que os seus estudos sobre Feijoo representarían dous modelos antagónicos xa que respondían a dúas interpretacións non coincidentes e, incluso, contrarias sobre a ciencia en España.

Por que o P. Feijoo? Por que motivos se concentra nel a contradición? Indubidablemente porque o P. Feijoo fora o escritor máis famoso de España no seu tempo, o máis xenial e independente, a proa da modernidade. Prestara atención a todos os temas que dunha ou doutra maneira lles interesaban aos intelectuais e ás clases

55 Carta do 26-IX-1879, en Ana María Freire López, «Feijoo en el siglo XIX: Concepción Arenal, Emilia Pardo Bazán y Marcelino Menéndez Pelayo», en José Checa Beltrán / Joaquín Álvarez Barrientos (coords.), El siglo que llaman ilustrado. Homenaje a Francisco Aguilar Piñal, 1996, 372.

56 Anos despois, alguén liberou este fondo de libros na Deputación de Ourense e circularon polo mercado do libro antigo. 
medias: as novas teorías científicas ${ }^{57}$ que circulaban por Europa, as artes, a música, as supersticións, os fenómenos da natureza, o matrimonio, a urbanidade como fórmula de convivencia social, etc.

Ademais porque Feijoo foi capaz de crear novos mecanismos de comunicación social, especialmente o ensaio, que facía moi atraente a súa lectura. Finalmente, porque utilizaba ás veces en forma destemida e valente a crítica social, cunha prosa irónica e algunha vez sarcástica, que rachaba con todos os moldes literarios que o precederan.

A partir da mesma obra aparecen dous discursos interpretativos de Concepción Arenal e Emilia Pardo Bazán que, sen forzar excesivamente a literalidade da obra do bieito galego, chegan a conclusións moi diferentes, o que revela as predeterminacións ideolóxicas de cada unha delas pero tamén a estudada neutralidade de Feijoo nos temas máis delicados.

Para C. Arenal o P. Feijoo era o xenio que podería cambiar o rumbo da ciencia española asumindo e propagando as teorías científicas de Newton, criticando a alianza do Altar e do Trono ou a estrutura do poder político que esmagaba calquera intento de independencia científica, é dicir, convertendo o movemento ilustrado nun verdadeiro Século das Luces, como sucedeu en moitos países de Europa, protagonizando, en definitiva, a revolución intelectual de Francia que desembocou na revolución política. Pero Feijoo optou por someterse aos poderes, producindo un movemento ilustrado que non rematou na revolución senón no Despotismo Ilustrado.

En troques, para E. Pardo Bazán Feijoo representa o máximo exemplo de fidelidade á nosa tradición intelectual. Puido ser o Voltaire español do século XVIII pero nel puido máis a fidelidade á tradición, é dicir, á Igrexa e ao poder absoluto do monarca que a ilusión de liderar un movemento que rompese a harmonía social que se vivía en España. Feijoo demostra, ademais, a falsidade do principio de que a ciencia en España non evolucionou como consecuencia dos atrancos que impuxo a Inquisición.

Velaí as dúas lecturas contrarias que fan estas dúas intelectuais galegas da obra do P. Feijoo.

57 Aínda que Marañón di, con admiración, que Feijoo dispuxo dun microscopio «tal vez el primero que vino a España», debemos situar esta afirmación entre as lendas que arrodearon a Feijoo. No ano 1687 publicouse en Valencia a obra de J. B. Corachan Methodus elaborandi componendique telescopia et microscopia, con gravados sobre diferentes tipos de microscopios. 